\title{
PENGARUH VOLUME KENDARAAN TERHADAP TINGKATKERUSAKAN JALAN PADA PERKERASAN LENTUR (FLEXIBLE PAVEMENT)
}

\author{
Hariman Al Faritzie ${ }^{1)}$, Bahder Djohan ${ }^{2)}$, Berri Wijaya ${ }^{3)}$ \\ Jurusan Teknik Sipil, Fakultas Teknik, Universitas Tridinanti Palembang \\ Jl. KaptenMarzuki No. 2446 Kamboja, Palembang 30129
}

\begin{abstract}
ABSTRAKSI
Jalan merupakan prasarana penting dalam transportasi yang dapat berpengaruh terhadap kemajuan bidang ekonomi, sosial, budaya maupun politik di suatu wilayah. Dengan melihat hal ini maka diperlukan peningkatan baik kuantitas maupun kualitas jalan yang memenuhi kebutuhan masyarakat. Penelitian ini bertujuan untuk mengetahui jenis-jenis kerusakan, persentase kerusakan jalan dan tebal pelapisan tambahan (Overlay) pada perkerasan lentur jalan Simpang Talang Jambe jalan AMD Sugiwaras. Melaksanakan survey secaralangsung di lapangan sehingga diperoleh berupa data primer seperti jenis - jenis dan jumlah dari komposisi kerusakan jalan dan jumlah LHR (Lalu Lintas Harian Rata-Rata) pada ruas jalan Simpang Talang Jambe - jalan AMD Sugiwaras. Analisis perhitungan tebal pelapisan tambahan (Overlay) dilakukan dengan menggunakan metode Analisa Komponen PU Bina Marga Tahun 1987. Berdasarkan hasil analisis maka diperoleh besar volume kendaraan pada ruas Jalan Simpang Talang Jambe sebesar 4581 kendaraan/hari/2 arah. Dan persentase kerusakan jalan sebesar 30,03\% dengan perhitungan tebal perkerasan lapisan tambahan (Overlay) dengan umur rencana 5 tahun sebesar $14 \mathrm{~cm}$ dan untuk umur rencana 10 tahun sebesar $17 \mathrm{~cm}$.
\end{abstract}

Kata kunci : LHR (Lalu Lintas Harian Rata-Rata), Persentase Kerusakan Jalan, Perkerasan Lentur (Flexible Pavement)

\section{PENDAHULUAN}

Jalan merupakan prasarana penting dalam transportasi yang dapat berpengaruh terhadap kemajuan bidang ekonomi, sosial, budaya maupun politik di suatu wilayah. Melihat hal ini maka diperlukan peningkatan secara kuantitas maupun kualitas jalan yang memenuhi kebutuhan masyarakat, baik untuk kenyamanan dan keamanan bagi pengemudi makajalan harus didukung oleh perkerasan yang baik.

Perkerasan jalan adalah campuran antara agregat dan bahan ikat yang digunakan untuk menerima beban lalu lintas. Jenis perkerasan jalan yang digunakan pada ruas jalan ini yaitu perkerasan lentur (flexible pavement).

Jalan simpang Talang Jambe sepanjang

$\pm \quad 2,5 \mathrm{~km}$ merupakan akses yang menghubungkan jalan Simpang Talang Jambe - jalan AMD Sugiwaras. Kondisi jalan disepanjang jalan ini mengalami banyak kerusakan. Hal ini disebabkan oleh besarnya volume kendaraan yang tidak sesuai dengan kapasitas jalan. Banyaknya kendaraan berat yang melewati jalan tersebut dikarenakan tingginya aktivitas pembangunan disekitar lokasi tersebut seperti pembangunan perumahan (cluster), pembangunan fly over simpang bandara, dan lain - lain sehingga membuat jalan tersebut menjadi akses jalan alternative dari atau menuju jalan Simpang Talang Jambe dan jalan AMD Sugiwaras.

Melihat fenomena tersebut, maka penulis berupaya menganalisis bagaimana pengaruh volume kendaraan yang melintas terhadap tingkat kerusakan pada ruas jalan tersebut serta mengevaluasi bagaimana kondisi eksisting kualitas perkerasan lentur dan juga rencana perbaikan di masa yang akan datang.

\section{TINJAUAN PUSTAKA}

\section{Pengertian Jalan}

Jalan adalah prasarana transportasi darat yang meliputi segala bagian jalan, termasuk bangunan pelengkap dan perlengkapannya yang di peruntukkan bagi lalulintas, yang berada pada permukaan tanah, di atas permukaan tanah, di bawah permukaan tanah dan/atau air, serta di atas permukaan air, kecuali jalan kereta api, jalan lori, dan jalan kabel.(Peraturan Pemerintah Nomor 34, 2006) 


\section{Volume Lalu Lintas}

Volume lalulintas adalah jumlah kendaraan yang melewati suatu penampang tertentu pada suatu ruas jalan tertentu dalam satuan waktu tertentu. volume lalu lintas ratarata adalah jumlah kendaraan rata-rata dihitung menurut satuan waktu tertentu, bisa harian yang dikatakan sebagai volume lalu lintas harian rata-rata/LHR Average daily traffic volume (ADT) atau volume harian ratarata tahunan/LHRT Annual verage daily traffic volume (AADT).

$\mathrm{LHRT}=\frac{\text { Jumlah Lalu Lintas dalam satu Tahun }}{360} \ldots .2 .1$
$\mathrm{LHR}=\frac{\text { Jumlah Lalu Lintas Selama pengamatan }}{\text { Lamanya Pengamatan }} . .2 .2$

Tabel 2.1Klasifikasi Jalan

\begin{tabular}{|c|c|c|}
\hline \multicolumn{3}{|c|}{ Menurut } \\
\hline Fungsi & Kelas & $\begin{array}{c}\text { LHR dalam } \\
\text { SMP }\end{array}$ \\
\hline Jalan Utama & Jalan Kelas I & $20.000>$ \\
Jalan & Jalan Kelas IIA & $6.000-20.000$ \\
Sekunder & Jalan Kelas IIB & $2.000-6.000$ \\
& Jalan Kelas IIC & $<2.000$ \\
Jalan & Jalan Kelas III & - \\
Penghubung & & \\
\hline
\end{tabular}

Sumber: Dirjen Bina Marga, 1987

\section{Perkerasan Jalan}

Perkerasan jalan merupakan lapisan perkerasan yang terletak di antara lapisan tanah dan roda kendaraan, yang berfungsi memberikan pelayanan kepada sarana transportasi, dan selama masa pelayanannya diharapkan tidak terjadi kerusakan yang berarti. (Silvia Sukirman 2003).

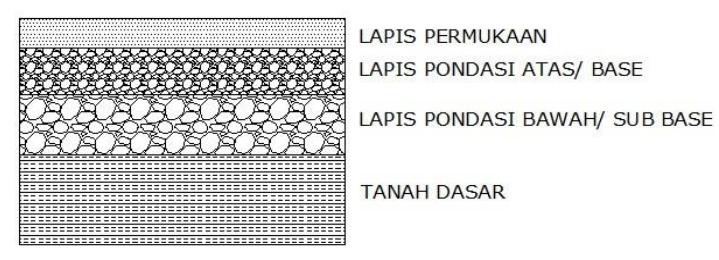

Gambar 2.1 Susunan Lapisan Perkerasan Lentur (Dirjen Bina Marga, 1987)

\section{Nilai Kerusakan Jalan (Nr)}

Nilai kerusakan jalan merupakan jumlah total dari setiap nilai jumlah kerusakan pada suatu ruas jalan.

Tabel 2.2 Urutan Prioritas Program Pemeliharaan Jalan

\begin{tabular}{|c|c|}
\hline Urutan Prioritas & Penanganan \\
\hline $0-3$ & Peningkatan \\
$4-6$ & Pemeliharaan Berkala \\
$>7$ & Pemeliharaan Rutin \\
\hline
\end{tabular}

Sumber: Dirjen Bina Marga, 1987

\section{LOKASI PENELITIAN}

Penelitian ini mengambil lokasi di ruas jalan Simpang Talang Jambe - jalan AMD Sugiwaras Kota Palembang. Situasi eksisting sebagai berikut: panjang ruas jalan tersebut \pm $2,5 \mathrm{~km}$, dengan spesifikasi 2 lajur $2 \operatorname{arah}(2 / 2$ UD) dengan ukuran lebar masing - masing lajur 3,00 m, lebar efektif jalur $6,00 \mathrm{~m}$ dan bahu jalan $0,60 \mathrm{~m}$.

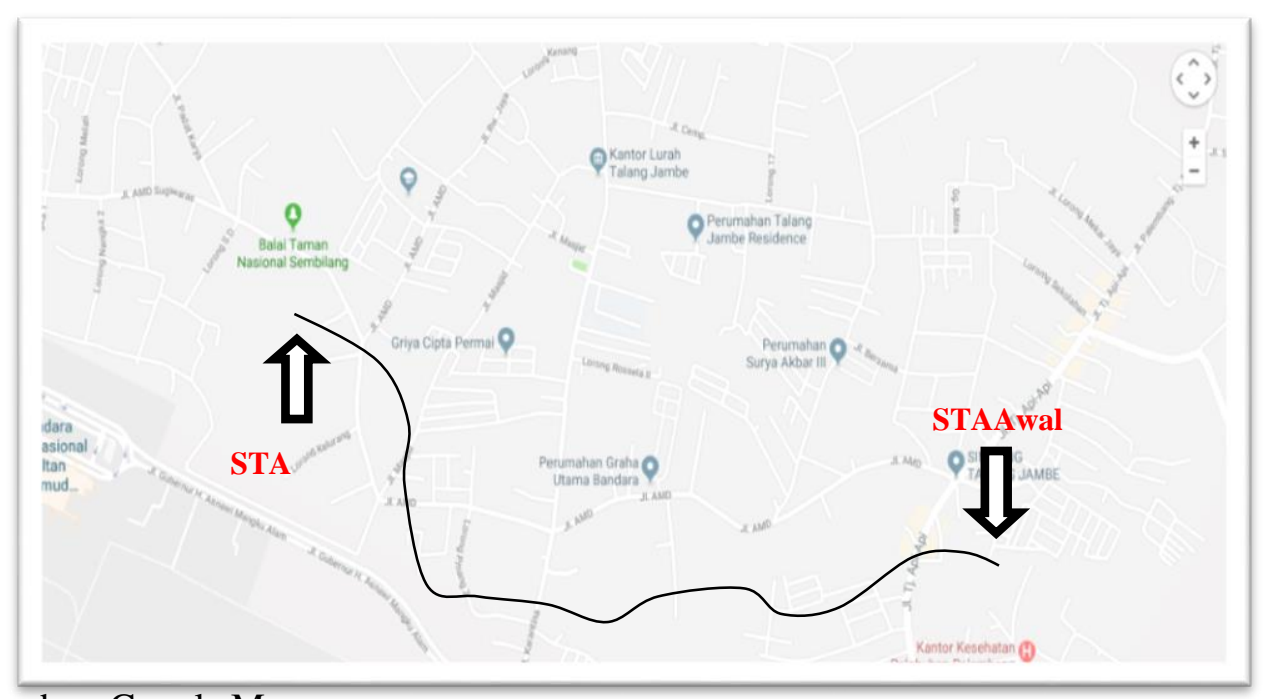

Sumber: Google Maps 


\section{METODOLOGI PENELITIAN}

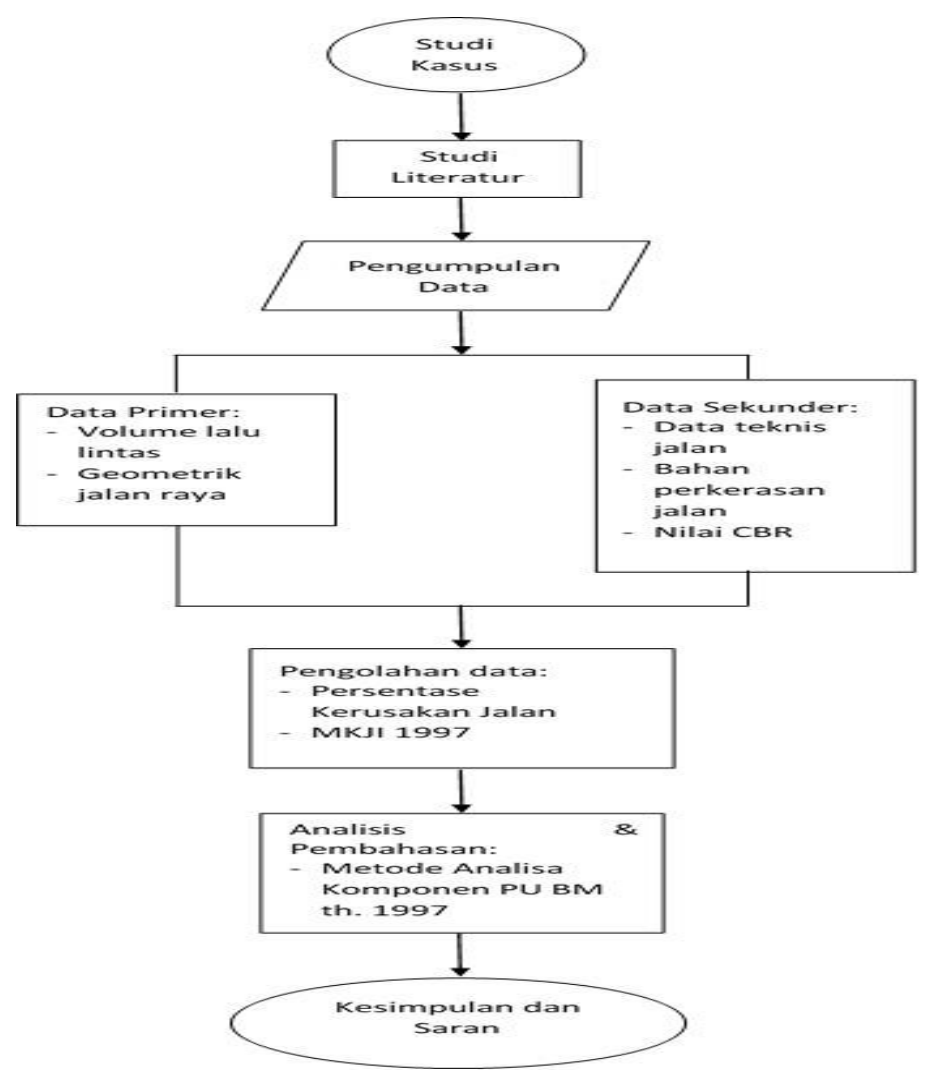

\section{ANALISA DAN PEMBAHASAN}

Hasil data yang diperoleh dari survey lapangan pada ruas Jalan Simpang Talang Jambe yang dilaksanakan pada hari Rabu tanggal24 Januari 2018 dilakukan selama 24 jam. Adapun data yang tidak diperoleh dari lapangan yaitu data dari instansi terkait. Hal ini di perlukan untuk mempermudah dalam menganalisa atau mengolah data tersebut. Dalam pengambilan data terbagi dalam data primer dan data sekunder, untuk data primer pengambilan data didapat dengan cara melakukan pengamatan dilapangan secara langsung atau melakukan survei lapangan.

Berdasarkan hasil survei lapangan, data yang di peroleh yaitu data geometrik pada ruas Jalan Simpang Talang Jambe yang dapat dilihat pada tabel dibawah ini :

\begin{tabular}{|l|l|}
\hline Nama Jalan & $\begin{array}{l}\text { Jl. Simpang Talang } \\
\text { Jambe }\end{array}$ \\
\hline Tipe Jalan & $2 / 2$ UD \\
\hline Lebar Jalur & $6,00 \mathrm{~m}$ \\
\hline Lebar Lajur & $3,00 \mathrm{~m}$ \\
\hline Lebar Bahu & $60 \mathrm{~cm}$ \\
\hline
\end{tabular}

\section{Volume Lalu Lintas}

Data volume lalu lintas diperoleh dengan melakukan survey secara langsung di lapangan. Survei dilakukan pada hari Rabu tanggal 24 Januari 2018. Data tersebut kemudian dianalisa untuk menentukan besar volume lalulintas pada ruas jalan yang menjadi objek penelitian. Rekapitulasi volume kendaraan dapat dilihat pada tabel dibawah ini.

\begin{tabular}{|l|l|l|l|l|}
\hline \multirow{2}{*}{ Periode } & \multicolumn{4}{|c|}{ Lalu Lintas Harian Rata-Rata (LHR) } \\
\cline { 2 - 5 } & $\begin{array}{l}\text { Kendara } \\
\text { an } \\
\text { Berat } \\
\text { (HV) }\end{array}$ & $\begin{array}{l}\text { Kendara } \\
\text { an } \\
\text { Ringan } \\
\text { (LV) }\end{array}$ & $\begin{array}{l}\text { Kendar } \\
\text { aan } \\
\text { Motor } \\
\text { (MC) }\end{array}$ & $\begin{array}{l}\text { Total } \\
\text { Kendaraan }\end{array}$ \\
\hline $\begin{array}{l}\text { Rabu } \\
11.00-19.00\end{array}$ & 1197 & 1462 & 6688 & 9347 \\
\hline $\begin{array}{l}\text { Rabu/Kamis } \\
19.00-03.00\end{array}$ & 113 & 436 & 1485 & 2034 \\
\hline $\begin{array}{l}\text { Kamis } \\
\text { 03.00-11.00 }\end{array}$ & 612 & 761 & 3788 & 5161 \\
\hline Jumlah & 1922 & 2659 & 11961 & 16542 \\
\hline
\end{tabular}

\section{Kondisi Kerusakan Jalan}

Kondisi kerusakan Jalan diperoleh dari hasil penelitian pada setiap ruas jalan. Dari semua ruas jalan yang diteliti jenis kerusakan yang terjadi hamper sama hasil perhitungan 
persentase kerusakan jalan dihitung per STA 100 agar dapat mengamati kerusakan jalan dengan jelas dan pengamatan dilakukan dengan melihat kerusakan jalan pada jalur yang menjadi objek penelitian. Berikut ini rekapitulasi jumlah kerusakan jalan

\begin{tabular}{|l|l|}
\hline \multirow{2}{*}{ JenisKerusakan } & Dimensi \\
\cline { 2 - 2 } & Luas $\left(\mathrm{m}^{2}\right)$ \\
\hline & Total \\
\hline RetakPinggir & 552,6 \\
\hline RetakSusut & 884,5 \\
\hline RetakBuaya & 1495,9 \\
\hline RetakSelip & 45,7 \\
\hline Retak Alur & 39,3 \\
\hline Lubang & 1487,2 \\
\hline
\end{tabular}

Dari hasil rekapitulasi kerusakan jalan didapat jenis kerusakan jalan yang paling dominan pada ruas jalan Simpang Talang Jambe adalah jenis kerusakan retak buaya sebesar 1495,9.

Dengan menjumlahkan seluruh kerusakan jalan per STA makadi dapat total kerusakan jalan sebesar 4505,2 $\mathrm{m}^{2}$.

Dari hasil survey geometric untuk luas jalan keseluruhan diketahui lebar jalan $6.00 \mathrm{~m}$, jumlah jalur 1, dan panjang jalan yang menjadi objek penelitian sepanjang $2500 \mathrm{~m}$. Maka luas jalan keseluruhan $15000 \mathrm{~m}^{2}(6 \mathrm{~m} \mathrm{x} 1$ jalur $\mathrm{x}$ $2500 \mathrm{~m}=15000 \mathrm{~m}^{2}$ ).

Adapun perhitungan persentase \% kerusakan dijalan Simpang Talang Jambe dapat dihitung dengan menggunakan persamaan 2.3

Nilai Persentase Kerusakan $(N p)$

$\mathrm{Np}=\frac{\text { Luas Jalan Rusak }}{\text { Luas Jalan Keseluruhan }} \times 100 \%$
$\mathrm{~Np}=\frac{4505,2}{15000} \times 100 \%=0,3003=30,03 \%$

Berdasarkan hasil perhitungan persentase kerusakan sebesar 30,03\%

Besarnya nilai persentase kerusakan diperoleh dari persentase luas permukaan jalan yang rusak terhadap luas keseluruhan bagian jalan yang ditinjau. Dengan di dapat persentase kerusakan jalan sebesar 30,03\% maka persentase tersebut berada diantara $10 \%$ - 40\% dengan kategori sedang dan nilai 5. Nilai Persentase kerusakan jalan $(\mathrm{Np})$ dapat di lihat pada tabel 2.6
Dengan didapat nilai persentase kerusakan (Np) kita dapat menentukan penanganan terhadap kerusakan jalan. Berdasarkan Tabel 2.9 didapat nilai persentase kerusakan sebesar 5 maka prioritas pemeliharaan jalan tersebut berada pada urutan prioritas 4-6 yaitu Pemeliharaan Berkala.

\section{Perencanaan Perkuatan Jalan Lama (Pelapisan Tambahan/Overlay)}

\section{1) Rencana}

Berdasarkan data dari PU Bina Marga Sumatera Selatan di dapat tebal lapis tambahan jalan lama 1 jalur, data lalulintas tahun 2018 dan umur rencana 5 tahun dan 10 tahun. Susunan perkerasan jalan lama : Laston $($ MS 590 $)=10 \mathrm{~cm} ;$ Batu pecah $($ CBR 80$)=20$ $\mathrm{cm}$; Sirtu $($ CBR 50) $=10 \mathrm{~cm}$. Hasil penelitian pada kondisi jalan menunjukan bahwa pada lapis permukaan Laston terlihat banyak Crack (retak), beberapa deformasi pada jalur roda (kondisi 40\%) akibat jumlah lalulintas yang melebihi perkiraan semula $\mathrm{FR}=1,0$

Dari hasil survei LHR di dapat jumlah volume kendaraan sebagai berikut :

\section{a) Data-data}

Kendaraan ringan 2 ton $=$ 2659

Kendaraan

Bus 8 ton $=12$

Kendaraan

Truk 2 as 13 Ton

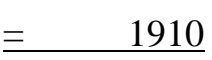

Kendaran

$\begin{array}{cc}\text { LHR } 2018 \underset{\text { Kendaraan/hari/2 }}{\operatorname{arah}(\text { Data Primer) }} & 4581\end{array}$

Untuk menghitung perkembangan lalulintas (i) dengan umur rencana 5 tahun dan 10 tahun dapat dilihat pada persamaan 2.5

$\left.\begin{array}{l}\text { Untuk } 5 \text { tahun }=5 \% \\ \text { Untuk } 10 \text { tahun= 4\% }\end{array}\right\} \begin{aligned} & \text { Sumber : Data PU } \\ & \text { Bina Marga } \\ & \text { Sumatera Selatan }\end{aligned}$

Bahan lapis tambahan Laston (MS 590) : (Campuran aspal keras dan agregat bergradasi menerus, dicampur, dihamparkan dan di padatkan dalam keadaan panas pada suhu tertentu)

\section{b) Penyelesaian}

Menghitung LHR kendaraan dengan menggunakan persamaan 2.5 untuk umur rencana 5 tahun dan 10 tahun sebagai berikut : 
LHR tahunke 5 (5 tahun)

Perkembangan lalulintas 5\%

$(1+0,05)^{5} \times 2659=3393,6$

LHR tahunke 10 (10 tahun)

Perkembangan lalulintas $4 \%$

$(1+0,04)^{10} \times 2659=3935,9$

LHR pada tahun ke 5 dan ke 10 (akhir umur rencana), rumus $(1+\mathrm{i})^{\mathrm{n}}$

\begin{tabular}{|l|l|l|}
\hline $\begin{array}{l}\text { Jenis } \\
\text { Kendaraan }\end{array}$ & $\begin{array}{l}\text { LHR UR 5 } \\
\text { Tahun } \\
\text { Kendaraan }\end{array}$ & $\begin{array}{l}\text { LHR UR 10 } \\
\text { Tahun } \\
\text { Kendaraan }\end{array}$ \\
\hline $\begin{array}{l}\text { Kendaraan } \\
\text { ringan 2 ton }\end{array}$ & 3393,6 & 3935,9 \\
$\begin{array}{l}\text { Bus 8 ton } \\
\text { Truk 2 as 13 } \\
\text { ton }\end{array}$ & 2437,7 & 17,7 \\
& & \\
\hline \multicolumn{2}{|c|}{ Setelah menghitung jumlah LHR } \\
\hline
\end{tabular}

maka dihitung Angka Ekivalen (E) pada Tabel 2.17 dan melihat beban sumbu kendaraan masing-masing sebagai berikut:

Kendaraan ringan 2 ton $(1+1) 0,0002+0,0002$ $=0,0004$

Bus 8 ton $(3+5)$

$0,0183+0,1410=0,1593$

Truk 2 as 13 ton $(5+8)$

$0,1410+0,9238=1,0648$

Untuk menghitung LEP harus mengetahui nilai Koefisien Distribusi Kendaraan (C) dapat dilihat pada Tabel 2.16 dan untuk perhitungan LEP menggunakan persamaan 2.6 dengan rumus sebagai berikut :

\section{Menghitung LEP :}

$$
\mathrm{LEP}=\sum_{\mathrm{j}=1}^{\mathrm{n}} \mathrm{LHR}_{\mathrm{j}} \times \mathrm{C}_{\mathrm{j}} \times \mathrm{E}_{\mathrm{j}}
$$

Kendaraan ringan 2 ton

$2659 \times 0,50 \times 0,0004=0,5318$

Bus 8 ton

$12 \times 0,50 \times 0,1593=0,9558$

Truk 2 as 13 ton

$\begin{array}{ll}1910 \times 0,50 \times 1,0648 & =1016,88 \\ \text { LEP } & =1018,36\end{array}$

Setelah mendapatkan nilai LEP kemudian menghitung LEA untuk umur rencana 5 tahun dan 10 tahun dengan menggunakan persamaan 2.7 dengan rumus dengan rumus sebagai berikut :

Menghitung LEA :

$$
\mathrm{LEA}=\sum_{j=1}^{n} \mathrm{LHR}_{\mathrm{j}}(1+\mathrm{i})^{\mathrm{UR}} \times \mathrm{C}_{\mathrm{j}} \times \mathrm{E}_{\mathrm{j}}
$$

Untuk perhitungan umur rencana 5 tahun sebagai berikut :

Kendaraan ringan 2 ton

$3393,6 \times 0,50 \times 0,0004=0,6786$

Bus 8 ton

$$
\begin{aligned}
& 15,3 \times 0,50 \times 0,1593 \quad=1,2186 \\
& \text { Truk } 2 \text { as } 13 \text { ton } \\
& \underline{2437,7 \times 0,50 \times 1,0648=1297,83}
\end{aligned}
$$

$=1299,72$

Untuk perhitungan umur rencana 10 tahun sebagai berikut :

Kendaraan ringan 2 ton

$3935,9 \times 0,50 \times 0,0004=0,7871$

Bus 8 ton

$17,7 \times 0,50 \times 0,1593 \quad=1,4098$

Truk 2 as 13 ton

$\underline{2827,3 \times 0,50 \times 1,0648=1505,25}$

$\mathrm{LEA}_{10}=1507,44$

Setelah mendapatkan hasil

perhitungan $\mathrm{LEA}_{5}$ dan $\mathrm{LEA}_{10}$ dilanjutkan dengan menghitung $\mathrm{LET}_{5}$ dan $\mathrm{LET}_{10}$ dengan menggunakan persamaan 2.8 dengan rumus sebagai berikut :

\section{Menghitung LET :}

LET $=1 / 2($ LEP + LEA $)$

$\mathrm{LET}_{5}=1 / 2\left(\mathrm{LEP}+\mathrm{LEA}_{5}\right)$

$=1 / 2(1018,36+1299,72) \quad=1159,04$

$\mathrm{LET}_{10}=1 / 2\left(\mathrm{LEP}+\mathrm{LEA}_{10}\right)$

$=1 / 2(1018,36+1507,44) \quad=1262,9$

Dengan diketahui nilai LEP, LEA, dan LET maka dapat menghitung LER (Lintas Ekivalen Rencana) dengan ketentuan factor penyesuaian untuk umur rencana 5 tahun dan 10 tahun dengan menggunakan persamaan 2.9 dengan rumus sebagai berikut :

\section{Menghitung LER :}

$\mathrm{LER}_{5}=\mathrm{LET}+\mathrm{UR} / 10$

$=1159,04 \times 5 / 10 \quad=579,52$

$\mathrm{LER}_{10}=\mathrm{LET}+\mathrm{UR} / 10$

$=1262,9 \times 10 / 10 \quad=1262,9$

Menentukan nilai DDT dengan menggunakan grafik korelasi DDT dan CBR. Untuk nilai CBR didapat dari data sekunder yang diperoleh dari PU Bina Marga Sumatera Selatan. Dengan diketahui nilai CBR tanah dasar 4,7\% maka nilai DDT dapat dilihat pada Gambar 4.1 Grafik Korelasi DDT dan CBR. 

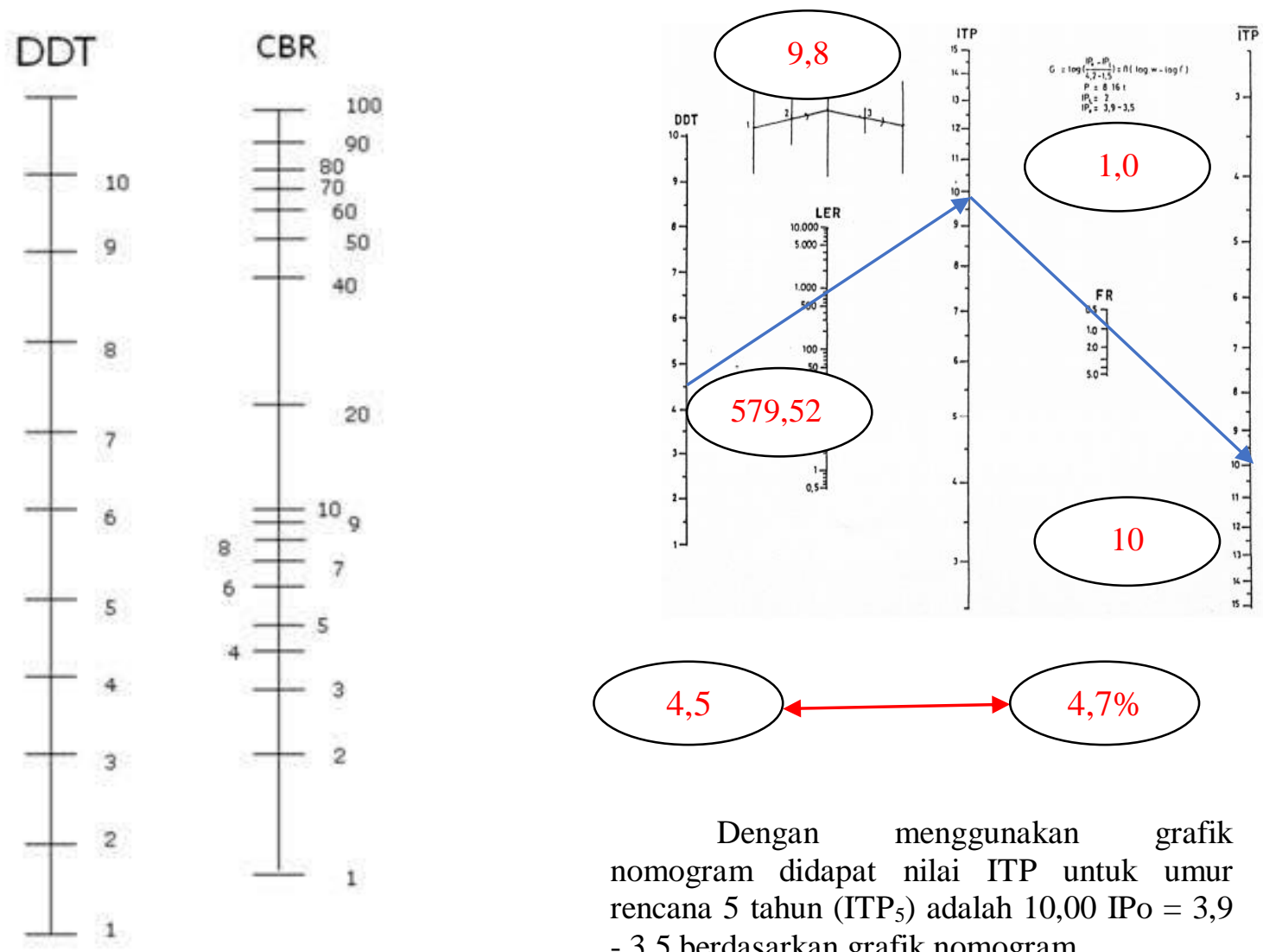

Dengan menggunakan grafik nomogram didapat nilai ITP untuk umur rencana 5 tahun $\left(\mathrm{ITP}_{5}\right)$ adalah $10,00 \mathrm{IPo}=3,9$ - 3,5 berdasarkan grafik nomogram.

Setelah menghitung $\mathrm{ITP}_{5}$ lalu menghitung $\mathrm{ITP}_{10}$ dengan cara yang sama menggunakan grafik nomogram dan diketahui $\mathrm{LER}_{10}=1262,9$ sebagai berikut :

CBR tanah dasar $=4,7 \%$ (Sumber PU Bina Marga) DDT $=4,5 ; \mathrm{IP}=2 ; \mathrm{FR}=1,0$ dan $\mathrm{LER}_{10}=1269,2$

Setelah mendapatkan semua nilai diatas, lalu mencari nilai ITP dengan menggunakan grafik nomogram pada gambar 2.11, dengan diketahui nilai $\mathrm{LER}_{5} 579,52$ dan nilai $\mathrm{LER}_{10}$ 1262,9 CBR tanah dasar 4,7\%, DDT 4.5, IP (Indeks Permukaan) 2 dan Faktor Regional 1,0 dapat dilihat pada Tabel 2.10 CBR tanah dasar $=4,7 \%$ (Sumber PU Bina Marga) DDT $=4,5$ $; \mathrm{IP}=2 ; \mathrm{FR}=1,0$ dan $\mathrm{LER}_{5}=579,52$

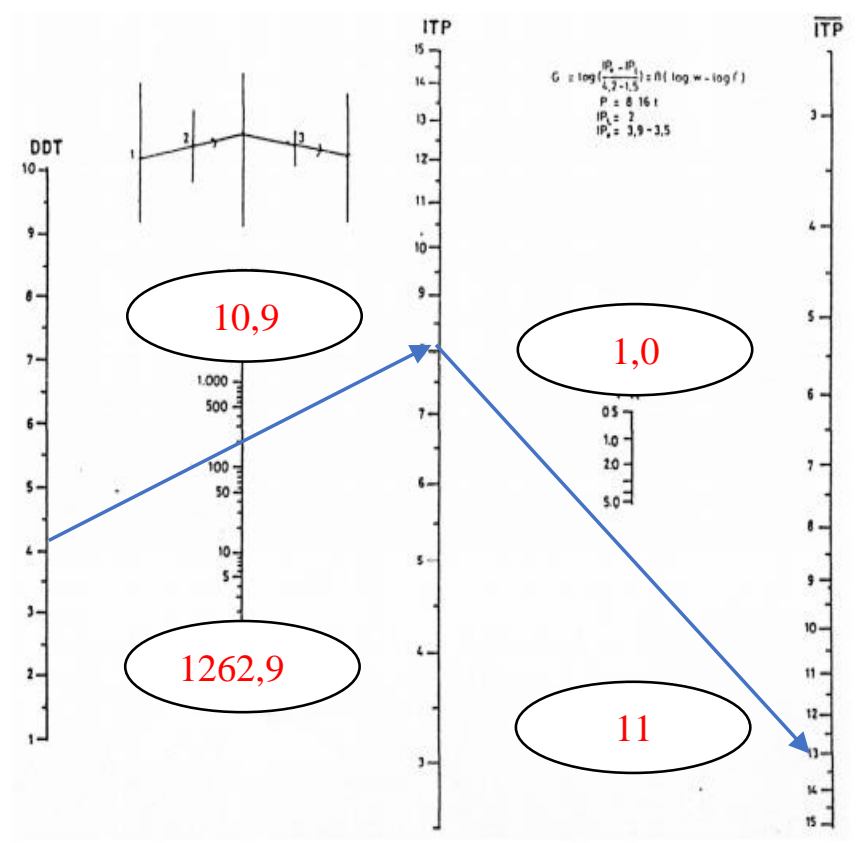


Dengan menggunakan grafik nomogram di dapat Nilai ITP untuk umur rencana 10 tahun $\left(\mathrm{ITP}_{10}\right)$ adalah 11,00 IPo $=3,9-3,5$ berdasarkan grafik nomogram.

Setelah mendapatkan ITP $_{5}$ dan ITP $_{10}$ dari grafik nomogram, lalu menetapkan tebal lapis tambahan dengan data yang di dapat dari PU Bina Marga Sumatera Selatan yaitu bahan perkerasan kekuatan jalan lama Laston (MS 590) 10 cm, Batu Pecah (CBR 80) $20 \mathrm{~cm}$, dan Sirtu (CBR 50) $10 \mathrm{~cm}$.

Menetapkan tebal lapis tambahan untuk Umur Rencana (UR) 5 tahun sebagai berikut dengan kekuatan jalan lama :

Laston (MS 590)

$=40 \% \times 10 \times 0,35=1,4$

Batu Pecah (CBR 80)

$=100 \% \times 20 \times 0,13=2,6$

Sirtu (CBR 50)

$=100 \% \times 10 \times 0,12=1,2$

ITP $=5,2$

- Umur Rencana (UR) 5 tahun :

$\triangle \mathrm{ITP}=\mathrm{ITP}_{5}-\mathrm{ITP}$

$=10-5,2=4,8$

$4,8=0,35 . \mathrm{D} 1$

$\mathrm{D} 1=13,71 \approx 14 \mathrm{~cm}$ Laston (MS

590)

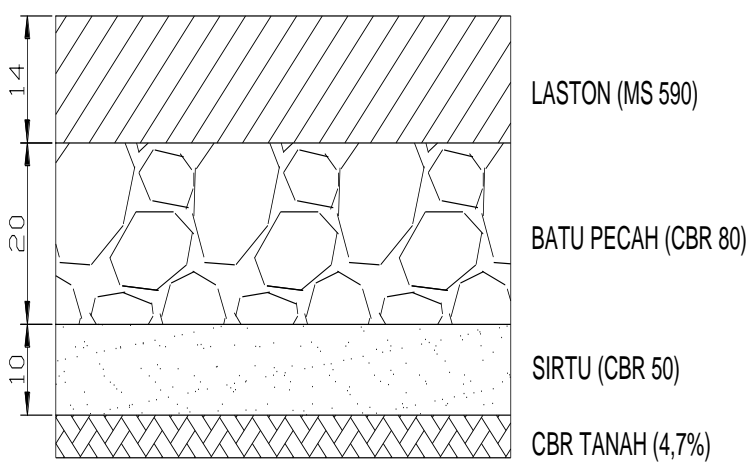

Tebal perkerasan lapis permukaan sebesar $14 \mathrm{~cm}$ untuk umur rencana jalan 5 tahun.

Menetapkan tebal lapis tambahan untuk Umur Rencana (UR) 10 Tahun dengan data dan cara perhitungan yang sama, dengan kekuatan jalan lama sebagai berikut :

Laston (MS 590)

$=40 \% \times 10 \times 0,35=1,4$

Batu Pecah (CBR 80)

$=100 \% \times 20 \times 0,13=2,6$

Sirtu (CBR 50)

$=100 \% \times 10 \times 0,12=1,2$

ITP $=5,2$

- Umur Rencana (UR) 10 tahun

$\Delta \mathrm{ITP}=\mathrm{ITP}_{5}-\mathrm{ITP}$

$=11-5,2=5,8$

$5,8=0,35 . \mathrm{D} 1$

$\mathrm{D} 1=16,57 \approx 17 \mathrm{~cm}$ Laston (MS

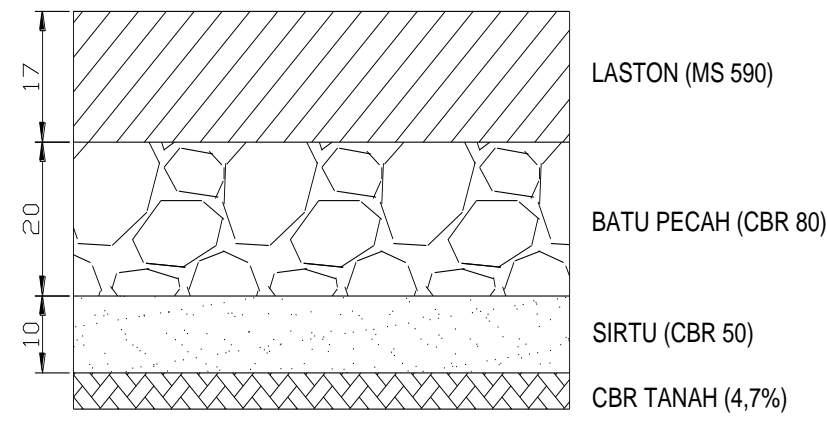

590)

Dari perhitungan diatas maka didapat tebal lapis permukaan sebesar 17 $\mathrm{cm}$ untuk umur rencana jalan 10 tahun.

\section{PENUTUP}

\section{Kesimpulan}

Berdasarkan hasil analisa dan perhitungan pada penelitian di Jalan Simpang Talang Jambe maka dapat disimpulkan :

1. Hasil analisis survei LHR di Jalan Simpang Talang Jambe diketahui volume kendaraan di Jalan Simpang Talang Jambe sebesar 4581 kendaraan/hari/2 arah.

2. Persentase kerusakan yang terjadi pada ruas Jalan Simpang Talang Jambe sebesar 30,03\%

3. Hasil perhitungan perencanaan tebal perkerasan lentur jalan dengan menggunakan metode analisa 
komponen pekerjaan umum (PU) Tahun 1987 diperoleh nilai pelapisan tambahan

\section{Saran}

Dari hasil penelitian, perhitungan, pembahasan dan kesimpulan yang ada maka dapat disampaikan beberapa saran untuk perbaikan pada ruas Jalan Simpang Talang Jambe agar lebih efektif dan efisien. Berikut saran yang dapat diberikan antara lain :

1. Pemeliharaan jalan sebaiknya dilakukan lebih cepat dari waktu yang telah direncanakan sebelumnya, agar kerusakan jalan yang terjadi tidak bertambah luas dengan menggunakan metode perbaikan yang sesuai pada masing-masing jenis kerusakan.

2. Membatasi volume kendaraan yang melewati jalan pada daerah yang menjadi objek penelitian, dengan cara mengalihkan kendaraan berat agar melewati jalur lain seperti jalan utama atau jalan raya serta membatasi muatan/tonase pada kendaraan kendara anangkutan barang.

3. Perbaikan pada ruas Jalan Simpang Talang Jambe sebaiknya tidak hanya dipusatkan pada perbaikan perkerasannya saja tetapi juga melakukan usaha peningkatan kapasitas jalan seperti misalnya, menambah lebar jalan atau penambahan lajur dikedua arah
(Overlay)denganumurrencana 5 tahunsebesar $14 \mathrm{~cm}$ dan untukumurrencana 10 tahun $17 \mathrm{~cm}$. dikarenakan pertumbuhan lalulintas dari waktu kewaktu semakin meningkat.

\section{DAFTAR PUSTAKA}

Departemen Pekerjaan Umum. 1987. Direktorat Jenderal Bina Marga, Petunjuk Perencanaan Tebal Perkerasan Lentur Jalan Raya dengan Metode Analisa Komponen.

Departemen Pekerjaan Umum. 1987. Direktorat Jenderal Bina Marga, Manual Kapasitas Jalan Indonesia (MKJI).

Nugroho, EkoAgus. 2013. Pengaruh Jumlah Kendaraan Terhadap Kerusakan Jalan Aspal Kelas II di Kabupaten Semarang; Fakultas Teknik Universitas Negeri Semarang, Semarang.

Putri, Vidya Annisah. 2016. Identifikasi Jenis Kerusakan Pada Perkerasan Lentur (Studi Kasus Jl. Soekarno Hatta, Bandar Lampung); Fakultas Teknik Universitas Bandar Lampung, Bandar Lampung.

Republik Indonesia. 2004. Undang - undang No.38, tentang Jalan.

Sukirman, Silvia. 1999. Dasar - dasar Perencanaan Geometrik Jalan, Nova, Bandung.

Sukirman, Silvia. 1999. Perkerasan Lentur Jalan Raya, Nova, Bandung. 